\title{
Инновационный потенциал Кемеровской области: структура, состояние ${ }^{1}$
}

Л.н. СТАРИКОВА, доктор социологических наук, Российский экономический университет им. Г.В. Плеханова Кемеровский институт (филиал)

Л.С. САГДЕЕВА, кандидат экономических наук, Кемеровский государственный университет, Кемерово

В статье рассмотрены составляющие инновационного потенциала Кемеровской области: человеческий и кадровый капитал, технико-технологический, экономический, информационный потенциалы. Предложена методика расчета интегрального показателя на основе указанных компонент и с ее помощью произведена оценка инновационного потенциала регионов Сибирского федерального округа. Показаны возможности использования предложенных показателей в инновационной политике регионов.

Ключевые слова: ресурсодобывающие регионы; инновационный потенциал региона; инновационность экономики; интегральный показатель инновационного потенциала

В соответствии с рекомендациями федерального центра, стратегии регионального развития как в среднесрочном, так и в долгосрочном периодах, предусматривают переход к новой концепции развития в условиях структурной перестройки экономики (в направлении от сырьевого к инновационному типу развития $)^{2}$. При описании ожидаемых сдвигов в 2020-2030-х гг. надежды возлагаются на прорывные технологии в различных отраслях [Старикова, Сагдеева, 2012], базовыми направлениями которых считаются: цифровые производственные технологии, нанотехнологии, альтернативная энергетика, информационные сети, биотехнологии растений, животных, медицинских препаратов [Кузык, Яковец, 2004. С. 624]. Вместе с тем законы инновационной динамики реализуются в мировом пространстве по весьма сложным схемам, потому что полные циклы

\footnotetext{
${ }^{1}$ Статья подготовлена в рамках выполнения НИРпо теме: «Эколого-экономический механизм функционирования минерально-сырьевых кластеров для обеспечения устойчивого развития добывающих регионов (приказ ФГБОУ ВО “Российский экономический университет им. Г. В. Плеханова” № 637 от 08.05.2018)»

2 Прогноз научно-технологического развития Российской Федерации на период до 2030 года. C. 6. URL: http://www.consultant.ru/document/cons_doc_LAW_157978/ (дата обращения: 21.08.2018).
} 
осуществления крупных научно-технологических нововведений крайне капиталоемки, и неизбежна достаточно узкая специализация стран при выборе инновационных приоритетов ${ }^{3}$.

Так, для нашей страны в целом и, в частности, для Кемеровской области как базового угледобывающего региона, сохранится ориентация на развитие в первую очередь топливно-энергетического комплекса. В ближайшей перспективе прогнозируется значительное повышение роли угля в топливноэнергетическом балансе страны. В Энергетической стратегии России до 2030 г. $^{4}$ декларируется необходимость увеличения добычи угля к 2030 г. по сравнению с 2008 г. на 31-44\% (326 и 427-470 млн т в год).

Масштабное применение угольного топлива в энергетике должно сопровождаться внедрением новых технологий переработки, которые позволят эффективно использовать его преимущества. До сих пор в электроэнергетике США доля применения угля составляет около 50\%, в Китае $-80 \%$, а в Польше достигает 96\% [Доклад.., 2009. С. 78]. Такому соотношению способствовали внедрение и развитие целого ряда экологически чистых и эффективных технологий сжигания угольного топлива.

Именно современные технологии переработки угля могут стать одним из основных направлений инновационного развития Кемеровской области. К тому же и инвестиционная активность региона сосредоточена в сырьевом секторе. Структура инвестиций в основной капитал в разрезе видов экономической деятельности в течение последних 10 лет принципиально не менялась. Так, сегодня их основная доля направляется на добычу угля (55,1\% в общей структуре инвестиций по крупным и средним предприятиям), развитие транспорта и связи (13,9\%), обрабатывающих производств $(8,7 \%)$, энергетики $(4,9 \%)^{5}$.

\footnotetext{
${ }^{3}$ Примаков Е. Россия перед выбором: [Эл. ресурс] // Российская газета. 2010. 14 января. № 4 (5083). URL: https://rg.ru/2010/01/14/primakov.htm (дата обращения: 22.08.2018).

${ }^{4}$ Энергетическая стратегия России на период до 2030 года (утв. распоряжением Правительства РФ от 13 ноября 2009 г. № 1715-р). [Эл. ресурс] // Информационно-правовой портал ГАРАНТ (дата обращения: 22.08.2018).

${ }^{5}$ Стратегия социально-экономического развития Кемеровской области на период до 2035 года/Проект. [Эл. ресурс] // URL: https://kemsu.ru/upload/2035.pdf?3.(дата обращения: 22.08.2018). С. 41.
} 


\section{Методы исследования}

Оценка инновационного потенциала позволит выявить возможности и основные направления приложения усилий как региона, так и страны в целом.

В работе мы опираемся на определения инновационного потенциала, зафиксированные в ГОСТ Р 54147-2010: «3.1.25. Инновационный потенциал: совокупность различных видов ресурсов, включая материальные, финансовые, интеллектуальные, информационные, научно-технические и иные ресурсы, необходимые для осуществления инновационной деятельности» ${ }^{6}$, а также авторов, придерживающихся ресурсного подхода [Прокофьев, 2013].

Инновационный потенциал региона объединяет в себе несколько комплексных характеристик, каждая из которых описывается системой показателей: человеческий и кадровый капитал (уровень образования и профессиональная подготовка населения); технико-технологический потенциал (ресурсная база НИОКР и инновационной деятельности); экономический потенциал (результативность НИОКР и инновационной деятельности) и информационный (применение информационно-коммуникационных технологий работниками организаций; использование ими компьютеров и компьютерных сетей, а также интеграция внутренних информационных систем и совместный доступ к информации внутри организации). Используемые комплексные (обобщающие) показатели отвечают российским и международным статистическим стандартам, применяемые методологические и методические подходы в их расчетах соответствуют принятым в отечественной статистике расчетам сводных показателей и индексов, а также практике построения региональных инновационных индексов ${ }^{7}$ и формирования соответствующих рейтингов под эгидой Европейской комиссии и других международных организаций ${ }^{8}$.

${ }^{6}$ ГОСТ Р 54147-2010. Национальный стандарт Российской Федерации. Стратегический и инновационный менеджмент. Термины и определения:(принят и введен в действие Приказом Росстандарта от 21.12.2010 № 901-ст)//Справочная система «Консультант Плюс»

${ }^{7}$ Целевые индикаторы реализации Стратегии инновационного развития Российской Федерации на период до 2020 года - (обновлено 22.08.2018) //URL: http://www.gks.ru/wps/ $\mathrm{wcm} /$ connect/rosstat_main/rosstat/ru/statistics/science_and_innovations/science/

${ }^{8}$ Методологические основы статистики науки и инноваций, определения ключевых показателей представлены в специализированном терминологическом словаре [Экономика знаний...2012]. 
По нашему мнению, именно имеющиеся ресурсы становятся той основой, на которой возникают (надстраиваются) соответствующие институты, развивается инфраструктура, складываются отношения, реализуются процессы, составляющие в итоге то, что понимается под «инновационной деятельностью». Таким образом, от понимания и осознания того, какие ресурсы имеются в регионе, насколько развиты/не развиты различные компоненты инноваций, зависят будущие изменения в конфигурации экономики и, в целом, обустройство жизни населения.

Конкретизирующие показатели комплексной оценки инновационного потенциала региона представлены в таблице 1 .

\section{Таблица 1. Показатели комплексной оценки инновационного потенциала региона,\%}

\begin{tabular}{|c|c|}
\hline $\begin{array}{c}\text { Частный } \\
\text { потенциал }\end{array}$ & Показатель \\
\hline \multirow{5}{*}{$\begin{array}{l}\text { Челове- } \\
\text { ческий } \\
\text { капитал }\end{array}$} & $\begin{array}{l}\text { Доля занятого населения в возрасте 25-64 лет, имеющего высшее образование, } \\
\text { в общей численности занятого населения соответствующей возрастной группы }\end{array}$ \\
\hline & $\begin{array}{l}\text { Удельный вес персонала, занятого исследованиями и разработками, к общей } \\
\text { численности занятых в регионе }\end{array}$ \\
\hline & Удельный вес лиц, имеющих ученые степени, к общей численности занятых в регионе \\
\hline & $\begin{array}{l}\text { Удельный вес студентов, обучающихся по образовательным программам высшего } \\
\text { образования (программы бакалавриата, специалитета, магистратуры) в общей } \\
\text { численности населения }\end{array}$ \\
\hline & $\begin{array}{l}\text { Удельный вес студентов, обучающихся по программам подготовки специалистов } \\
\text { среднего звена, в общей численности населения }\end{array}$ \\
\hline \multirow{7}{*}{$\begin{array}{l}\text { Производ- } \\
\text { ственный }\end{array}$} & $\begin{array}{l}\text { Удельный вес организаций, осуществлявших технологические инновации в отчетном } \\
\text { году, в общем числе обследованных организаций непромышленной сферы }\end{array}$ \\
\hline & Доля продукции высокотехнологичных и наукоемких отраслей в ВРП \\
\hline & $\begin{array}{l}\text { Количество патентов на } 10000 \text { человек занятого населения в регионе. Число па- } \\
\text { тентов на изобретения, выданных Роспатентом российским заявителям, в расчете } \\
\text { на } 1 \text { млн чел. населения }\end{array}$ \\
\hline & $\begin{array}{l}\text { Доля организаций промышленного производства и сферы услуг, осуществлявших } \\
\text { технологические инновации, в общем числе обследованных организаций }\end{array}$ \\
\hline & $\begin{array}{l}\text { Доля инновационных товаров, работ, услуг в общем объеме отгруженных товаров, } \\
\text { выполненных работ, услуг организаций промышленного производства и сферы услуг }\end{array}$ \\
\hline & $\begin{array}{l}\text { Доля инновационных товаров, работ, услуг в общем объеме экспорта организаций } \\
\text { промышленного производства и сферы услуг }\end{array}$ \\
\hline & $\begin{array}{l}\text { Удельный вес принципиально новых технологий в общем числе разработанных } \\
\text { передовых производственных технологий }\end{array}$ \\
\hline \multirow{2}{*}{$\begin{array}{l}\text { Технико- } \\
\text { технологи- } \\
\text { ческий }\end{array}$} & Коэффициент обновления основных фондов \\
\hline & Удельный вес основных фондов в ВРП \\
\hline
\end{tabular}




\begin{tabular}{|l|l|}
\hline \multicolumn{1}{|c|}{$\begin{array}{c}\text { Частный } \\
\text { потенциал }\end{array}$} & \multicolumn{1}{c|}{ Окончание табл. 1} \\
\hline \multirow{4}{*}{$\begin{array}{l}\text { Экономизатель } \\
\text { ский }\end{array}$} & $\begin{array}{l}\text { Доля затрат на технологические инновации, в общем объеме отгруженных товаров, } \\
\text { выполненных работ, услуг организаций промышленного производства и сферы услуг }\end{array}$ \\
\cline { 2 - 3 } & $\begin{array}{l}\text { Удельный весзатратнаисследованияиразработки, нацеленныенаразвитиеэкономики, } \\
\text { в общем объеме внутренних затрат на исследования и разработки }\end{array}$ \\
\hline \multirow{2}{*}{$\begin{array}{l}\text { Информа- } \\
\text { ционный } \\
\text { (электрон- } \\
\text { ный бизнес) }\end{array}$} & $\begin{array}{l}\text { Доля организаций, размещавших заказы на товары (работы услуги) в Интернете, } \\
\text { в общем числе обследованных организаций }\end{array}$ \\
\cline { 2 - 3 } & $\begin{array}{l}\text { Доля организаций, получавших заказы на выпускаемые товары (работы, услуги) } \\
\text { по Интернету, в общем числе обследованных организаций }\end{array}$ \\
\hline
\end{tabular}

На основе названных компонент инновационного потенциала и их показателей мы рассчитали интегральный показатель, который позволяет получить представление о текущем инновационном состоянии региона, степени использования имеющихся инновационных возможностей, говорит о его восприимчивости к внедрению инновационных технологий и может служить объективным критерием для сравнения потенциала разных территорий.

\section{Предпосылки перехода к новому укладу в России и в регионе}

Выделим основные предпосылки перехода национальной и региональной экономики к новому технологическому укладу.

1. Ориентация на развитие топливно-энергетического комплекса. Страна является поставщиком дорогостоящих и невозобновляемых природных ресурсов.

2. Высокая концентрация капитала в добывающих отраслях, в том числе в газовой и нефтедобыче, электроэнергетике, в то время как обрабатывающая промышленность показывает слабые конкурентные позиции на мировом рынке.

3. Объем инновационной продукции (работ, услуг) демонстрирует тенденцию с снижению. Так, в 2016 г. в РФ объем инновационных товаров (работ, услуг) составил 4364,3 млрд руб., из него на организации, осуществляющие технологические инновации, приходилось 3967,8 млрд руб. ${ }^{9}$ (рис. 1, 2).

\footnotetext{
${ }^{9}$ Статистика науки и образования. Вып. 4. Инновационная деятельность в РФ. Инф.стат. мат. М.: ФГБНУНИИ РИНКЦЭ, 2017. - 92 с. [Эл. pесурс] URL: http://csrs.ru/archive/ stat_2017_inno/innovation_2017.pdf (дата обращения: 20.08.2018 г.)
} 


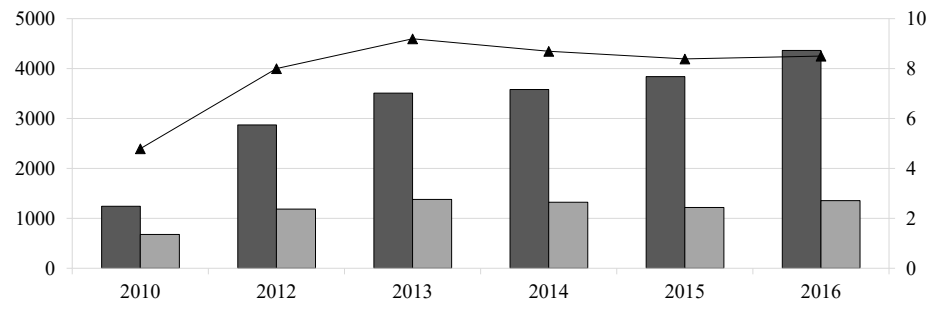

Объем отгруженных инновационных товаров, работ, услуг в действующих ценах, млрд руб. (левая шкала)

Объем отгруженных инновационных товаров, работ, услуг в постоянных ценах 2005 г., млрд руб (левая шкала).

Удельный вес инновационных товаров, работ, услуг в общем объеме отгруженных товаров, выполненных работ, услуг, \% (правая шкала)

Puc. 1. Динамика объема инновационных товаров (работ, услуг) крупных и средних организаций в РФ в 2010-2016 гг.

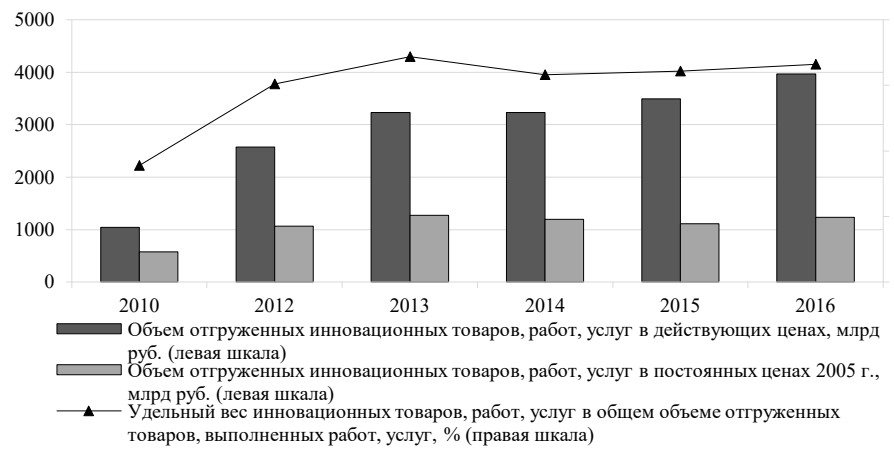

Puc. 2. Динамика объема инновационных товаров (работ, услуг) крупных и средних организаций, осуществляющих технологические инновации в РФ в 2010-2016 гг.

Как видно на диаграммах, несмотря на номинальный рост объемов, при пересчете показателей в сопоставимых ценах, удельный вес инновационной продукции после непродолжительного роста 2010-2012 гг. начал снижаться и по всему кругу организаций, и по организациям, осуществлявшим технологические инновации. До сих пор ни тем, ни другим не удалось повторить собственные показатели 2013 г. При этом относительно 2010 г. объем инновационной продукции (работ, услуг) в сопоставимых ценах вырос в два раза.

4. Снижение инвестиций в основной капитал в наиболее технологичных секторах промышленности. Анализ структуры 
инвестиций по видам экономической деятельности (рис. 3) показывает устойчивое снижение их доли в выпуске машин и оборудования, электронного и оптического, электротехники, производстве транспортных средств, а также в производстве и распределении электроэнергии, газа и воды, которые и являются драйверами технологического развития [Гребенников, Старикова, 2013].

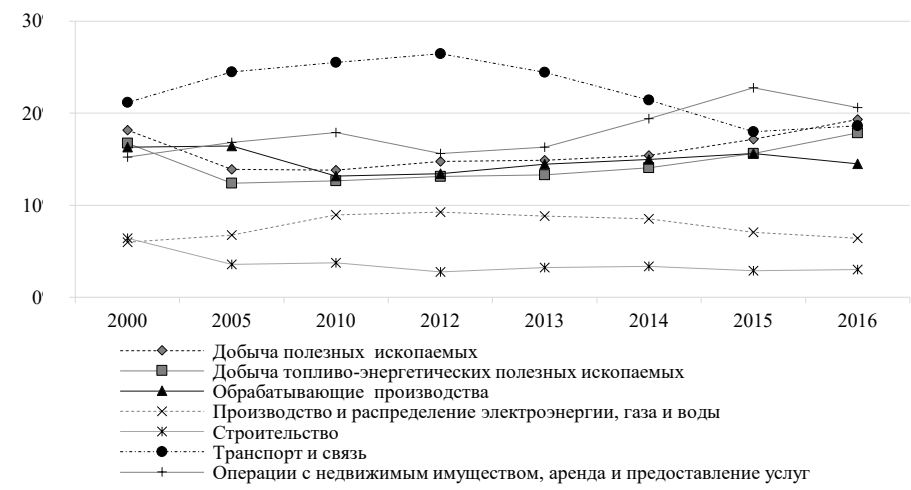

Источник: построено авторами по данным: Россия в цифрах. 2017: Краткий стат. сб. Росстат. М., 2017. 511с.

Puc. 3. Динамика структуры инвестиций в основной капитал по основным видам деятельности, \% к общему объему инвестиций в РФ за 2000-2016 гг.

Снижение затрат на инновации в технологичных секторах экономики обусловлено сокращением в структуре инвестиционных вложений доли бюджетных инвестиций (с $8,2 \%$ в 2010 г. до 5,9\% в 2016 г.) и займов других организаций (с $6,1 \%$ до 5,4\% соответственно $)^{10}$. Отметим, что в исследуемый период львиная доля инвестиций была направлена либо в экспортоориентированные отрасли (угледобыча, металлургия), либо в сверхприбыльные проекты с малыми сроками окупаемости (телекоммуникации, торговля, коммерческие услуги).

Основными отраслями для инвестиций в 2016 г. по-прежнему являлись добыча полезных ископаемых (19,33\%), в том числе добыча топливно-энергетических полезных ископаемых

\footnotetext{
${ }^{10}$ Россия в цифрах. 2017: Краткий стат. сб. Росстат. М., 2017. С. 427.
} 
$(17,85 \%)$, обрабатывающие производства $(14,51 \%)$, транспорт и связь $(18,63 \%)$, операции с недвижимым имуществом, аренда и предоставление услуг (20,62\%).

\section{Развитие инновационного потенциала Кузбасса}

В Кемеровской области развитие инновационного потенциала $(4,33 \%)$ заметно отстает от среднего уровня по стране $(6,57 \%)$ и от общего показателя по Сибирскому федеральному округу (СФО) (5,46\%) (табл. 2).

\section{Таблица 2. Показатели комплексной оценки инновационного} потенциала в 2010 г., 2017 r.

\begin{tabular}{|c|c|c|c|c|c|c|c|c|c|c|c|c|}
\hline \multirow[t]{2}{*}{$\begin{array}{c}\text { Субъект } \\
\text { СФО }\end{array}$} & \multicolumn{2}{|c|}{$\begin{array}{c}\text { Челове- } \\
\text { ческий } \\
\text { капитал }\end{array}$} & \multicolumn{2}{|c|}{$\begin{array}{c}\text { Производ- } \\
\text { ственный } \\
\text { потенциал }\end{array}$} & \multicolumn{2}{|c|}{$\begin{array}{c}\text { Техноло- } \\
\text { гический } \\
\text { потенциал }\end{array}$} & \multicolumn{2}{|c|}{$\begin{array}{c}\text { Эконо- } \\
\text { мический } \\
\text { потенциал }\end{array}$} & \multicolumn{2}{|c|}{$\begin{array}{c}\text { Информа- } \\
\text { ционный } \\
\text { потенциал }\end{array}$} & \multicolumn{2}{|c|}{$\begin{array}{c}\text { Интеграль- } \\
\text { ный по- } \\
\text { казатель } \\
\text { иннова- } \\
\text { ционного } \\
\text { потенциала }\end{array}$} \\
\hline & 2010 & 2017 & 2010 & 2017 & 2010 & 2017 & 2010 & 2017 & 2010 & 2017 & 2010 & 2017 \\
\hline $\begin{array}{l}\text { Томская } \\
\text { область }\end{array}$ & 6,31 & 7 & 14,17 & 10,52 & 2,13 & 1,94 & 3,81 & 7,55 & 32,3 & 29,5 & 7,48 & 7,95 \\
\hline $\begin{array}{l}\text { Новоси- } \\
\text { бирская } \\
\text { область }\end{array}$ & 6,01 & 5,7 & 8,67 & 12,87 & 3,02 & 2,36 & 3,78 & 3,53 & 18,3 & 22,71 & 6,41 & 6,74 \\
\hline PФ & 4,45 & 4,17 & 8,58 & 10,3 & 1,9 & 1,88 & 4,23 & 5,2 & 24,3 & 29,1 & 5,95 & 6,57 \\
\hline СФО & 3,71 & 3,68 & 6,01 & 7,47 & 2,08 & 1,93 & 3,13 & 3,59 & 20,5 & 25,4 & 4,95 & 5,46 \\
\hline $\begin{array}{l}\text { Респуб- } \\
\text { лика } \\
\text { Бурятия }\end{array}$ & 3,24 & 3,22 & 5,58 & 7,07 & 2,35 & 3,12 & 1,52 & 2,63 & 22,7 & 22,37 & 4,3 & 5,3 \\
\hline $\begin{array}{l}\text { Омская } \\
\text { область }\end{array}$ & 3,08 & 2,75 & 5,31 & 6,96 & 1,89 & 1,57 & 7,08 & 5,19 & 20,1 & 23,43 & 5,35 & 5,16 \\
\hline $\begin{array}{l}\text { Красно- } \\
\text { ярский } \\
\text { край }\end{array}$ & 3,09 & 3,2 & 4,65 & 5,47 & 1,36 & 1,77 & 2,72 & 4,24 & 19,4 & 26,55 & 4,01 & 5,11 \\
\hline $\begin{array}{l}\text { Алтай- } \\
\text { ский } \\
\text { край }\end{array}$ & 2,02 & 2,48 & 6,86 & 7,69 & 2,99 & 1,91 & 1,83 & 2,59 & 17,1 & 24,98 & 4,2 & 4,73 \\
\hline $\begin{array}{l}\text { Кеме- } \\
\text { ровская } \\
\text { область }\end{array}$ & 1,81 & 2,14 & 3,59 & 9,83 & 1,98 & 2,21 & 1,07 & 1,2 & 28 & 27,5 & 3,29 & 4,33 \\
\hline $\begin{array}{l}\text { Забай- } \\
\text { кальский } \\
\text { край }\end{array}$ & 1,53 & 1,55 & 4,52 & 9,98 & 1,73 & 2,28 & 1,4 & 1,61 & 18,4 & 23,1 & 3,15 & 4,2 \\
\hline
\end{tabular}




\begin{tabular}{|c|c|c|c|c|c|c|c|c|c|c|c|c|}
\hline \multirow{3}{*}{$\begin{array}{c}\text { Субъект } \\
\text { СФО }\end{array}$} & \multirow{2}{*}{\multicolumn{2}{|c|}{$\begin{array}{c}\text { Челове- } \\
\text { ческий } \\
\text { капитал }\end{array}$}} & \multirow{2}{*}{\multicolumn{2}{|c|}{$\begin{array}{c}\text { Производ- } \\
\text { ственный } \\
\text { потенциал }\end{array}$}} & & & & & & Окоң & ччание & табл. 2 \\
\hline & & & & & \multicolumn{2}{|c|}{$\begin{array}{c}\text { Техноло- } \\
\text { гический } \\
\text { потенциал }\end{array}$} & \multicolumn{2}{|c|}{$\begin{array}{c}\text { Эконо- } \\
\text { мический } \\
\text { потенциал }\end{array}$} & \multicolumn{2}{|c|}{$\begin{array}{c}\text { Информа- } \\
\text { ционный } \\
\text { потенциал }\end{array}$} & \multicolumn{2}{|c|}{$\begin{array}{c}\text { Интеграль- } \\
\text { ный по- } \\
\text { казатель } \\
\text { иннова- } \\
\text { ционного } \\
\text { потенциала }\end{array}$} \\
\hline & 2010 & 2017 & 2010 & 2017 & 2010 & 2017 & 2010 & 2017 & 2010 & 2017 & 2010 & 2017 \\
\hline $\begin{array}{l}\text { Иркут- } \\
\text { ская } \\
\text { область }\end{array}$ & 3,63 & 3,15 & 5,5 & 4,33 & 2,08 & 1,48 & 3,31 & 2,25 & 17,3 & 27,87 & 4,73 & 4,17 \\
\hline $\begin{array}{l}\text { Респуб- } \\
\text { лика } \\
\text { Алтай } \\
\end{array}$ & 2,32 & 1,96 & 5,19 & 4,7 & 1,81 & 2,24 & 2 & 2,07 & 22,1 & 28,14 & 3,95 & 4,13 \\
\hline $\begin{array}{l}\text { Респуб- } \\
\text { лика } \\
\text { Тыва }\end{array}$ & 2,65 & 2,63 & 7,49 & 4,14 & 2,48 & 2,53 & 2,52 & 0,42 & 15,2 & 20,85 & 4,52 & 2,99 \\
\hline $\begin{array}{l}\text { Респуб- } \\
\text { лика } \\
\text { Хакасия }\end{array}$ & 1,89 & 2,17 & 3,63 & 2,83 & 2,21 & 1,95 & 0,52 & 0,31 & 25,4 & 27,89 & 2,88 & 2,53 \\
\hline
\end{tabular}

Источник: составлена авторами по данным Росстата.

Хотя регион находится в русле общей тенденции к развитию всех компонент инновационного потенциала, по динамике производственной и технологической составляющих он - в числе лидеров, что объясняется инвестиционными предпочтениями его ведущих экспортных отраслей. Производственный потенциал Кузбасса с 2010 г. по 2017 г. вырос в 2,7 раза, технологический в 1,1 раза. Инновации связаны с увеличением доли продукции высокотехнологичных и наукоемких отраслей в ВРП (с 14,1\% в 2010 г. до 15,9\% - в 2017 г). При этом в целом в РФ коэффициент, характеризующий технико-технологическую компоненту, практически остался на том же уровне (1,9 в 2010 г. против 1,88 в 2017 г.) за счет снижения удельного веса основных фондов в ВВП.

Отметим, что несмотря на относительно невысокие показатели интегральной оценки инновационного потенциала Кузбасса, за последние семь лет ему удалось значительно сократить разрыв. Прирост потенциала в регионе составил $31,6 \%$ против $10,4 \%$ в целом по РФ (рис. 4).

В снижение динамики интегральной оценки в России в целом большой вклад внесла, в частности, кадровая компонента: на протяжении пяти лет неуклонно сокращалась численность докторантов и аспирантов (в среднем на $2 \%$ в год), а также удельный вес студентов вузов (более $30 \%$ ) в общей численности населения. 
В Кемеровской области «кадровый вопрос» тоже стоит довольно остро: хотя число докторантов и аспирантов в исследуемый период выросло (незначительно), доля студентов сократилась почти вдвое (с 3,5\% в 2010 г. до 1,9\% в 2017 г. от общей численности населения). При этом регион теряет население, в том числе и выпускников школ (суммарно за последние семь лет из него уехало 520,6 тыс. чел. (приехало на 27,3 тыс. чел. меньше) ${ }^{11}$.

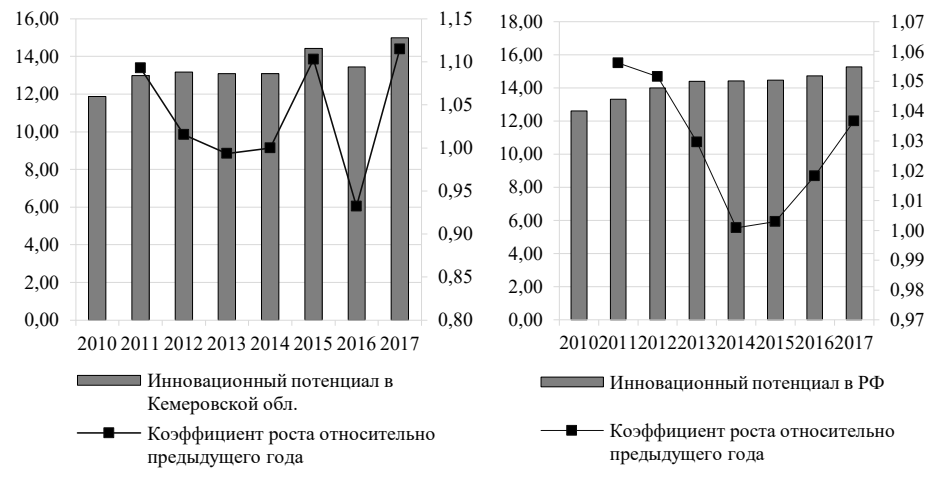

Puc. 4. Интегральный показатель инновационного потенциала в РФ и Кемеровской области за 2010-2017 гг.

Применение методики оценки инновационного потенциала в отношении регионов Сибирского федерального округа позволило выявить лидеров инновационного развития.

Результаты анализа позволили сделать вывод, что лидирующие позиции в СФО по показателям роста инновационного потенциала на протяжении исследуемого периода занимает Томская $(7,95)$ и Новосибирская области $(6,74)$. Самый низкий уровень реализации инновационного потенциала среди рассматриваемых регионов у Республики Тыва $(2,99)$ и Бурятии $(2,53)$.

Методика позволяет на основе анализа отдельных компонент интегрального показателя определить «болевые точки» и выделить приоритетные направления инновационной политики регионов, позволяющих преодолеть негативные тенденции. Скажем, для Бурятии самые проблемные зоны - информатизация и развитие

\footnotetext{
${ }^{11}$ Стратегия социально-экономического развития Кемеровской области на период до 2035 года/Проект. [Эл. ресурс] // URL: https://kemsu.ru/upload/2035.pdf?3.(дата обращения: 22.08.2018). С. 16.
} 
человеческого капитала (образование, здравоохранение), в Республике Тыва - экономическая компонента (увеличение затрат на исследования и разработки) и производственный потенциал (доля инновационной продукции). Властям Кемеровской области стоит уделить больше внимания развитию технологического потенциала (модернизации основных фондов, внедрению новых технологий).

Таким образом, инновационный потенциал является ключевым фактором развития всех сфер социально-экономической деятельности, задержка в этом процессе может привести область к переходу к негативному сценарию развития. В случае Кемеровской области - это практически полная переориентация на сырьевые секторы экономики, все более углубляющееся отставание от мирового уровня промышленности, потеря научного и кадрового потенциала и в целом экономическая деградация. Однако для выработки конкретных мер требуется более глубокое исследование в русле заданных направлений.

\section{Литература}

Гребенников А.В., Старикова Л.Н. Инновационное развитие как основа повышения конкурентоспособности тяжелого машиностроения в Кемеровской области//Горный журнал. 2013. № 5. С. 69-72.

Доклад о развитии человеческого потенциала в Российской Федерации в 2009 году/Под ред. С.Н. Бобылева. М.: ПрООН, 2009. 184c.

Кузык Б.Н., Яковеи Ю.В. Россия - 2050: стратегия инновационного прорыва: монография. М.: Экономика, 2004. С. 601-613.

Прокофьев К. Ю. Инновационный потенциал региона: сущность, структуpa// Стратегия развития региона. 2013. № 30(309). С. 12-18.

Современные тренды инновационного развития экономики: Коллективная монография/ Я.В. Коженко, А. В. Катаев, Т. М. Катаева, Н.В. Лихолетова, Е. Л. Макарова, Л.В. Шаронина. Под ред. Я. В. Коженко. Уфа: ОМЕГА САЙНС, 2016. 108 c.

Старикова Л.Н, Сагдеева Л.С. Инновационность экономики региона как предпосылка повышения качества человеческого капитала // Вестник КемгГУ. 2012. № 4. С. 324-331.

Экономика знаний в терминах статистики: наука, технологии, инновации, образование, информационное общество: [словарь / Г.И. Абдрахманова, Н. В. Городникова, Л.М. Гохберг и др.; науч. ред. Л. М. Гохберг]. М.: Экономика, 2012. 240 c. 


\section{Summary}

Starikova L.N., Russian university of Economics after G. V. Plekhanov Kemerovo Institute (branch)

Sagdeeva L.S., Department of Economics Kemerovo State University, Kemerovo The Innovative Potential of the Kemerovo Region: Structure, Status

The article considers components of innovation potential of the Kemerovo region. It proposes the integral indicator to evaluate innovation potential of regions in Siberian Federal District. It presents indicators for each component of innovation potential.

Innovation; innovation potential of a region; innovation economy; the integral indicator of innovative potential

\section{References}

Grebennikov A.V., Starikova L.N. (2013). Innovacionnoe razvitie kak osnova povysheniya konkurentosposobnosti tyazhelogo mashinostroeniya v Kemerovskoj oblasti. Gornyj zhurnal. No. 5. Pp. 69-72. (In Russ.).

Doklad o razvitii chelovecheskogo potenciala v Rossijskoj Federacii v 2009 godu (2009). Moscow Publ., PrOON. 184 p. (In Russ.).

Kuzyk B.N., Jakovec Ju.V. (2004). Rossija - 2050: strategija innovacionnogo proryva: monografija. Moscow. Jekonomika Publ., 624 p. (In Russ.).

Prokof'ev K. Yu. (2013). Innovacionnyj potencial regiona: sushhnost', struktura. Strategija razvitija regiona. No. 30 (309). Pp.12-18. (In Russ.).

Sovremennye trendy innovacionnogo razvitija jekonomi-ki: Kollektivnaja monografija. Ufa. OMEGASAJNS Publ., 2016. 108 p. (In Russ.).

Starikova L. N. Sagdeeva L.S. (2012). Innovacionnost ekonomiki regiona kak predposylka povysheniya kachestva chelovecheskogo kapitala. VestnikKemgGU. No. 4. Pp. 324-331. (In Russ.).

Ekonomika znanij v terminah statistiki: nauka, tehnologii, innovacii, obrazovanie, informacionnoe obshhestvo. Moscow. Jekonomika Publ., 240 p. (In Russ.). 